\title{
QUALITY OF SCHOOL LIFE FORSTUDENTS DIAGNOSED WITH DEPRESSION:AN EXPLORATORY STUDY
}

\author{
Melanie F. Bactasa ${ }^{1}$, and Caroline T. Sumande ${ }^{2}$ \\ ${ }^{1 \& 2}$ Polytechnic University of the Philippines, Quezon City Branch \\ *Caroline T. Sumande, e-mail: ctsumande@gmail.com
}

\begin{abstract}
This phenomenological study explores to contribute in developing mental health support system and services through an in-depth understanding of the quality of school life for students diagnosed with depression. It aimed to describe, identify influences and understand their experienced and perceived school life. Analysis indicated that school support system such as having friends, welcoming student services staff and participation in various student organizations found to be significant influences for them to experience quality of school life. On the other hand, perceived relationship with their teachers and parents as well as their personal uncertainty for their future career is expressed as challenges towards the attainment of quality school life.
\end{abstract}

Keywords:

mental health services, quality of school life, student with depression, support system

Article Received: 18 October 2020, Revised: 3 November 2020, Accepted: 24 December 2020

\section{Introduction}

The right to education has been translated at the heart of UNESCO's mission and the Declaration of Human Rights in 1948 as a fundamental human right. This right to education is one of the key principles underpinning the Education 2030 Agenda and Sustainable Development Goal 4 (SDG4) adopted by the international community. SDG 4 is rights-based and seeks to ensure the full enjoyment of the right to education as fundamental to achieving sustainable development.

Education in itself is said to be, an empowering right and one of the most powerful tools by which economically and socially marginalized children and adults can lift themselves out of poverty and participate fully in society (UNESCO, 2019).

This has made education as a fundamental right that should be enjoyed by all learners of all walks of life regardless of his/her position in the society. This gives way to the implementation of inclusive education as it values diversity and the unique contributions each student brings to the classroom. In a truly inclusive setting, every child feels safe and has a sense of belongingincluding also, those with psycho-social disability.
Worldwide, mental health issues and concerns such as depression became one of the major problem with estimated 300 million people affected(WHO, 2018) and known as social contagion phenomenonas (Eyre et al., 2017)thatdeveloped and triggered outfromsomeone'ssocial environment.

Along with this opportunity for equal access to education, academic institution as an important part of the microsystem of the learneris required to provide quality school life. A number of literature (e.g. Bryk, Lee \& Holland, 2013;Flynn, 2013) hasstressedthat the quality school life is a significant aspect in the learning process. Understanding students' views of quality of school life should light on ways to promote and assure the quality of school education (Thien, 2018).

The Association for University and College Counseling Center Directors (2013), showed statistically that the number of students with psychological problems was a growing concerned in their school; it was noted that thirty six (36) percent of the students came for counselingshowed signs and symptoms of depression.Depression can have broad negative effects on students' academic work and comfort in 
school (Crundwell and Killu, 2010).Hence, schools need to provide a variety of interactive and productive engagements to increase students' success(Schneider, 2017). This gives rise to understanding students' psychological concerns in relationship with their academic experiences as necessary to build a more holistic measure of school quality.

Parehk (2017) defined depression as a common and serious clinical illness that negatively affects how a person feels, thinks and acts. It causes feelings of sadness and a loss of interest in activities once enjoyed. It can lead to a variety of emotional and physical problems and can decrease a person's ability to function at school and at home.Depression is said to be a dominantly prevalent issue of younger generations including those in college now a days(Sreeramareddy, Shankar, Binu, Mukhopadhyay, Ray, and Menezes, 2007).

In the Polytechnic University of the Philippines Quezon City Branch with almost 2000 plus student population, of $30 \%$ of which availed the individual counseling services have found to have mental health issues. Data shows that from school year 2017 to present, eleven (11) of them were identified with signs and symptoms of mood related conditions including depression (PUP Quezon City Guidance and Counseling Office Records, October 2019).Accordingly, American Psychological Association (2017) reported the increase of percentage in students seeking appointments in counseling have depression (49 percent), the second major concerns by the students next to anxiety. Among of the identified school factors were related in trying to fit in, maintain good grades, complying with academic requirements, handling break-ups, familial issues, financial problems and homesickness (Sarokhani et. al., 2013).

This study viewed the relevance of Tangen(2009) conceptualization of quality of school lifebased on the understanding of the students' experiences and perspectives related to school. Analysing and understanding aspects of the meanings of experiences as narrated by the students with regards to their quality school life's either negatively or positively could mean no definite and exact definition of the topic. Tangen (cited by Javaal, 2007) students may experience and perceived the same thing differently and the quality of school life of a learner may change from time to time.

Studies as generally described by individuals with depressive episodes are challenging. Concentrating on class discussions and interacting people was difficult (Wang et al., 2012).Hence, broad research on the impact of social support on depression in the adolescent and general population should be considered (Robotham, 2008).Determining specific social support that protects mental health and quality of school life is essential for the emotional, social and academic adjustment of university students (Alimoradi et al., 2014).

Since, there is a few review of the literature to date, and by the identified lack of qualitative research, this study aims indescribing, identifying influences and understanding the quality of school life for students with depression. It is vital to understand how this quality school lifefor them. Understanding the lived experiences and support needed to ensure student development and success is critical to help students succeed in theirpersonal and academic endeavors (Evans et.al., 2009).

Hence, the formulation of the following research questions to provide answers or information in response to the purpose of the study: 1) How do students experience and perceive school life?and 2) What influences their school life?

The general goal of the researcher was to explore and contribute on existing literatures by developing mental health support system and services responsive towards the attainment of 
quality school life for students with psycho-social condition such as depression.Additional findings from this study include engaging school stakeholders such as school administrators, teachers, staff, parents and students to best help and support these students.

\section{Methods}

Participants were identified using purposive sampling. Purposive sampling involves identifying and selecting individuals or groups of individuals that are especially knowledgeable about or experienced with a phenomenon of interest (Cresswell\& Plano Clark, 2011). In this study, the following criteria were considered: must be a student diagnosed with depression; bonafide student with at least one (1) year residency to the Polytechnic University of the Philippines Quezon City Branch; enrolled for First Semester Academic Year 2019-2020; and voluntarily disclosed their condition and submitted copies oftheir psychological evaluation report and certification signed by their attending Clinical Psychologist or Psychiatristto the Guidance and Counseling Office.

In order for this study to address the research questions, several delimitationswere established. This study was limited to a very specific population- students previously diagnosed with depression. Demographic profiles such as sex, age, year level, status and program (course)of the students were not considered.In addition, this study did not attempt describe, identify influences and understand quality school life of any other students with the same condition in Polytechnic University of the Philippines Branches and Satellite Campuses other than Quezon City Branch.

This qualitative study used phenomenological approach to describe, identify influences and understand the quality school life of the students diagnosed with depression. The researcher believes that understanding their subjective experienced and perceived quality school life can provide academic institutions such as Polytechnic University of the Philippines Quezon City Branch where the participants are bonafide students with responsive interventionsthrough developing mental health support system and services. Phenomenology aimed to accurately describe the phenomenon without a pre-existing knowledge to framework, but framing truth to the facts (Groenewald, 2004). Interpretive phenomenological inquiry gains credibility by capturing the experience as it is lived and perceived by participants (Benner, 2000). This study is credible when it represents an accurate account of the participants' experiences, as defined by the participants themselves.

As experience and perception are main focus in the quality school life of the students, the researcher asked the participants to describe their experiences and then freely express their perception related to the topics. The researcher wanted them to express this through identifying influences to their school life. Responses were analyzed according to a phenomenologicalthematic analysis model. Thematic analysis was used as it purports to enable researcher to use predetermined or a priori themes (Ryan and Bernard 2003) from existing research to structure the analysis of data and then describe patterns of experience within a qualitative data set (Ayres 2008).

\section{The Researchers' Role}

The researchers are composed of the Accreditation Coordinator, who always wishes that the University provides better services to the students, and with the Guidance Counselor who, in turn, regularly monitor the participants, biases are present. The researchers acknowledge their biases might impact their interpretation of the research findings. They made an effort in this study to set aside biases, to maintain objectivity, 
and to reflect only those results that the data bears. The Accreditation Coordinator and the Guidance Counselor has closed coordination with and access to the participants' involved, which grants their entry to the research site. Ethical considerations included the potential for bias, as Accreditation Coordinator and Guidance Counselor and fully identify by research participants.

The researchers' intent was to respect the rights, privacy, and autonomy of research participants to the fullest extent possible. It's their hope that results benefited those students with mental health issues and concerns especially those with depressive episodes by raising awareness on their perceived quality of school life and hence providing them responsive and comprehensive school support prevention and intervention program in general.

\section{Data Sources}

Triangulation was utilized in this study.The researcher used the following data sources in her aimed to increase the credibility and validity of the results of the study such as interview method, observations and used of pertinent documents available at the Guidance and Counseling Office. The main point is to gain good understanding from different perspectives of an investigated phenomenon. That should not necessarily mean cross -checking data from at least two sources or methods and confirming it is correct or not. It's more to increase the level of knowledge about something and to strengthen the researcher's standpoint from various aspects (Nechoska, 2015).

The two participants were between 19 to 25 years old, both female and were diagnosed with depression a year prior to the conduct of this study. They were interviewed at the Guidance and Counseling Office of the said university on the their availability set earlier of October 2019. The said interview range from 20 to 35 minutes.
The interview deliberately encourages the participants to describe their experiences in their own words. An experienced qualitative researcher (Silvia Krumm) gave feedback on the first interview to ensure the quality of the in-depth nature of the interviews. The interviews aimed to elicit an in-depth subjective experience of each participant on their perceived quality school life.

\section{Data Collection}

Individual face-to-face interviews were held as data gathering procedure for purposes of describing the participant's quality school life based on their lived experiences. A semistructured interview guide was used to keep the interactions focused on the topic of research while allowing individual perspectives and experiences to emerge (Patton, 2012).

The interviews with the students were conducted on the language wherein the participants were comfortable expressed with. To capture as fully as possible, both verbal and nonverbal responses were noted. The researcher noted down the nonverbal gestures and cues observed during the interview while verbatim responses of the participants, interviews were tape-recorded and transcribed by the researcher immediately after each session.

Furthermore, observations were done in school premises especially when the students are with their friends, classmates or even in their class. Also, pertinent documents on hand such as case counselling notes were reviewed and checked to have in-depth understanding of the student's lived experiences in school.

\section{Data Analysis}

Relevant data from interviews, observations conducted and documents on hand were collected earlier of October 2019. The participants' response to the central questions: "How do they experience and perceive school life?"and "What influences their school life?". 
After transcribing the recorded interviews with the participants, the researchers then began to do spotchecking to guarantee quality control of the transcript. Significant statements were then extracted from participants' both verbal and nonverbal responses and coded for recurring concepts that make reference to the priori themes (Ryan and Bernard 2003). Statements were subsequently compared and clustered into sub-themes, and further reduced into either one or more of the theoretically derived themes. Thematic analysis was used as a means of identifying, analyzing and reporting patterns in the data (Braun \& Clarke, 2006).

Important behavioral observations with the participants and previous case notes of the participants available at the Guidance Office were well taken.

\section{Ethical Considerations}

Several ethical considerations were taken into account to ensure that the study was conducted in an appropriate manner (Babbie \& Mouton, 2010). To comply with ethical considerations in conducting research, both verbal and written consent was obtained prior to the scheduled interview set according to the availability of the participants.

The researchers verbally sought the approval of the participants. Retaliation of the details about the study was given during the interview, such as: (1) the purpose of the research study; (2) confidentiality clause of information obtained from the interviews; and (3) the use of pseudonyms to ensure anonymity of participants. Also, participants were requested to sign a copy of the letter of informed consent as evidence of their willingness to participate in the study.

\section{Results}

This qualitative phenomenological study engages thematic analysis of the experiences and perspectives of the students based on data collected in the study. Thematic analysis involves the identification and analysis of themes and patterns of similarity within qualitative research (Braun \& Clark, 2006).

From the data analyses, the following themes were emerged: 1) Poor Teacher-Student Classroom Engagement; 2) Dysfunctional ParentChild Relationships; 3) PersonalUncertaintyfor Future Career; and 4) Welcoming School Support System. (Please see Appendix 2-Schematic Summary of Identified Major Themes and its Subthemes).

\section{Theme 1. Poor Teacher-Student Classroom Engagement}

Theme 1 can be explained by five subthemes which includes teachers' insensitivity, lesson-focused teaching, high expectations for students and non-disclosure of condition with subject teachers. From the analysis, it can be understood that teacher establishes poor interpersonal relationships with their students. Though, they regard their teachers with mastery on their taught subjects, students developed negativity such as non-disclosure of their condition and perceived teachers as straightforward and careless in some of their choice of words.

\section{Subtheme A. Teacher's Insensitivity}

Students perceived some of their teachers as careless for there words especially in class discussions. Mean remarks and offensive jokes of the teachers affected them that they regard it as personal attacks to them or to their friends.

Students stated the following:

a. "go away with gay friends, you might get pregnant"

b. "hmmmmm..some are just making dramas and excuses"

c. "no special streatment in this class"

Subtheme B. Lesson-Focused Discussion 
This subthemes focused on the teaching style of which the teachers used. Teacher engages teacher-centered approach, a method wherein the teacher is actively involved in teaching while the students are passive and receptive in the learning process.

The following relevant statements quoted from the students:

a. "came to the lecture room right away, we didn't even ask if we were ok"

b. " in fairness, he knows what he is teaching... that's all..."

\section{Subtheme C. High Expectations for Students}

High expectations of the teacher from their students is another concern of the participants, they felt pressured to those subjects that teachers set too much expectations of "knowing all" topic discussed. The high expectations principle means holding high expectations for all students relative to academic performance in class.

Participant quoted the following:

a."You should know, didn't you go to Senior High ...?" know..."

b. "You're college right? Then you should

c." Expect all students were good and knew the topics"

\section{Subtheme D. Non-Disclosure of Condition with Subject Teachers}

The said subtheme emerged due to develop negative thoughts and irrationalities of the participants towards their teachers. Teacher's insensitivity as one of the subtheme contribute for non-disclosure of their condition especially to the subject teachers.

The perception is illustrated in the following statement:

a. "hmmmm (silent)......I only told ma'am Oli-Adviser

b. "I don't have any plan of telling my subject profs about my condition..."

c. "they might not understand..."

\section{Theme 2. Dysfunctional Parent-Child Relationships}

Another theme that emerged focused on the persistent narratives of the participants regarding their dysfunctional relationships with their parents and how they were being labeledat home. Uninvolved or unsupportive parents to their children' academic life greatly had undesirable impact with children well-being.

\section{Subtheme A. Uninvolved and Unsupportive Parents}

Student regards their parents as their number one stressor. It is prevalent that students shared common experiences having neglectful parents. Neglectful parenting according to Baumrind (cited by Dauliwal, 2019) are characterized by parents that are emotionally detached and unresponsive to the child. The emotional needs of the child such as need for appreciation, security, love, nurturing are overlooked. They greatly impact the child' total well-being. The following statements were narrated by participants:

a. "since grade school, I can't feel there presence"

b. "no support at all"

\section{Subtheme B. Stigmatizing Attitudes of Parents}

Aside from a being uninvolved and unsupportive of parents to their children, they highlighted the negative attitudes of their parents towards their condition. "Stigma is present at home"; sadly they experienced being devalued, labelled and judged by their parents for their condition.

Both participants freely expressed how they experienced being stigmatized by their parents as stated:

a. "I don't need to see a psychiatrist. I'm just making dramas....long sigh....

b. " So are you crazy?" she don't bothered anyway" 
c. "I'm having my personal check up without her knowledge, she's negative about it"

d. "for her, you're crazy already if your taking med."

\section{Theme 3. Personal Uncertaintyfor Future Career}

Having mental health condition, participants viewed their future career with ambiguity. They perceived that their program was unrelated to what they really wanted. They emphasize their experiences on their irrationalities with those major and math-related subjects that triggered their episodes. Furthermore, they account their current program as useless later in life for they wished to pursue on a career associated to their interest. Two identified subthemes were students: Academic struggles with major and math-related subjects and Perceived Unrelatedness between their Program and Career Interest

\section{Subtheme A. Academic Struggles on Major and Math-related Subjects}

Another trigging school factors that contribute to student episodes were identified as their personal struggle to understand their major subjects. They are unmotivated and lack understanding on the lesson especially those that need analytical and critical thinking.

Relevant statements are presented:

a. "I don't expect many math subjects, I have weak spots in math, two more accounting subjects! grrrr..."

b. "I have difficulty with our topic, I think of shifting because I don't like it. "

$c . "$ There are days that are heavy, I guess

because of the subjects and profs on that day"

d. "90 percent of the class do not understand or I do not understand..."

\section{Subtheme B. Perceived Unrelatedness between Enrolled Program and Career Interest}

Participants admitted that they are forced to enroll on the program their parents wanted for them or based on recommendations since they don't have a choice to defend what they really wanted. With such circumstances, they perceived their program unrelated and not align to their career interest.

a. "I guess I just convinced myself because ICT was my strand during Senior High and this is what my daddy wants ",

b. "I was surprised with my course, I felt like I couldn't use it later, I liked events, I loved handicrafts.

c. "I thought about changing course because I was thinking about work later"

\section{Theme 4. Welcoming School Support System}

Despite negative experiences and perception mentioned in earlier themes, participants optimistically shared their lived experiences in school. Availability of their support system such as the support from their friends, approachable and friendly students services staffand active involvement with different student organizations and activities were considered by them as significant influences for their quality school life.

\section{Subtheme A. Supportive Friends in School}

Students highly appreciated the presence of their friends in facing their personal battle with depression especially in accomplishing and completing their academic requirements. They acknowledged the care and support of their friends as major influenced to their wellness and quality school life to the extent of appreciating friends more than their own family.

a. "They are very supportive, especially in making my requirements"

b. "The more I spend with my friends, I build my strength"

c. "When I was studying, they were there, they were my support group " 

courses"

d. "I have a group of friends with different

e."I learned to value friends rather than my family ... I would be more affected if they were not around"

\section{Subtheme B. Availability of Student-Support Services Staff}

Other positive experiences the students shared focused on having friendly and approachable staff in school. Student support services given by different offices such as Security, Admission, Registrar and Guidance Office were mentioned by the students.

a. "it is very helpful for me to go for guidance, I feel relax ..."

b. "Those who are in the office are kind and approachable"

c. "At the gate even the guard inspect my bag, it's okay, he just doing his job, what is important that he is kind"

d. "registrar and admission staff are approachable, they do their job"

\section{Subtheme C. Involvement in Different Organizationsand Activities in School}

Students' participation in various student organizations and activities in school was enjoyable and productive coping of the students to lessen their depressive episodes. Quality school life was mentioned based on their engagement to activities they liked and enjoyed with.

They mentioned about:

a. "I've been busy with activities at the school 'd like"
b. "the officers are kind"
c. "busy but happy, I am entertained"

\section{Discussion}

As a whole, findings of this study shows that generally students with depressive episodes opted to share both negative and positive experiences and their perspectives with school life. Same viewpoints were described by Tangen (cited by Javaal, 2007) in her study about the quality of school life, emphasizing the importance of listening and subjective experiences of the child; in this study attention has been given to the student's own experiences and perceptions about their school life as well as significant influences.

Results of the study brought four major themes that would describe their school life; these are the 1.) Poor Teacher-Student Classroom Engagement; 2.)Dysfunctional Parent-Child Relationships; 3.)Personal Uncertainty for Future Career; and 4. Welcoming School Support System.

The first major theme highlighted on the recurrence of statements regarding poor teacher's engagement to assess students' profile such as being careless and insensitive to some of their chosen words. This is also supported by the study conducted by Gay (2001), teachers who are not familiar with or understand the cultural difference of their students will not be able to address the differences appropriately in their classrooms. Teachers must become knowledgeable about their students' cultural backgrounds so they can translate that knowledge into effective instruction, create a culturally responsive classroom, build relationships with the students, engage students in the learning process, and improve academic performance (Gay, 2001). Though students have high regards for teachers in terms of their mastery on the subject matter, however; they discouraged teacher-centered approach as a method wherein the students are passive and receptive in the learning process. More so, as indicated in the case note record (July 2019) of one of the student, concerned was on her difficulty to adjust on the teaching strategies. Furthermore, high expectations for students trigger them to feel pressured with regards to their academic performance. Lastly, due to receptive, passive and great pressure experienced and perceived from their teachers, they develop negative 
thoughts not to reveal or disclosed their condition with their teachers.

The second major theme discusses the type of relationships they have with their parents. They emphasized how parents influenced and contributed to their depressive episodes as freely expressed by them. Neglectful parenting style such as lack of psycho-social support and stigmatizing attitudes of parents undesirably impact to their negativity to experience quality school life. There is evidence in the literature suggesting that negative family interactions contribute to youth depression (Goodman \&Gotlib, 1999; Sheeber \& Sorenson, 1998), with family support and conflict being two particularly important factors. Stice, Ragan, and Randall (2004), for example, reported that youth perception of low parental support was related to adolescent depression. Several studies have included measures of family conflict, and found it to predict risk for depression among youth (Kane \& Garber, 2004; Marmorstein \& Iacono, 2004).

The third major theme focused on their peronal uncertainty and ambiguity they perceived on their future career. Two subthemes were developed namely: academic struggles with their major and math-related subjects and pereceived unrelatedness of their current program and career interest. Lack of motivation and lack of interest with the subjects are consistent and explained by their perceived conflict with their current program and what they really want or interest with. Also, these were linked to the first major theme, poor teacher-student classroom engagement, in this case; lack of appreciation and encouragement for students to improve their performance. Moreover, as mentioned in the study of Law et.al. (2014) the primary tenet of Pryor and Bright's Chaos Theory of Career is that our world is full of change and unpredictability. Learner with high levels of anxiety and low tolerance of uncertainty embrace unexpected career changes.
The fourth and the last theme emerged and illustrated with optimistic sharing of their quality school life. Students appreciated the presence of their support system such as having friends who supported them academically to accomplish their academic requirements. Academic requirements were not mentioned as a school trigging factors with their condition due to friends' academic support. This is in contrast to the finding of Predelli (2015) students mental health problem includes meeting school demands such as academic requirements, aside from family demands.

Hence, in this study, friends are recognized by them as the most important significant person more than their parents with regards to their academic life. Accordingly, as observed in the classroom, student lounge and within the vicinity of the school campus, student seemed enjoying the company of their friends. Interestingly, friendly and approachable staff as well as their active participation in various student organizations and activities in school helped them manage their depressive episodes. In contrast, a lack of social support from peers and school are determinants of mental health problems including depressive symptoms among university students (Bukhari \& Afzal, 2017; Safree \& Dzulkifli, 2009), and has a negative impact on quality of life for students (Dafaalla et al., 2016). Research evidence indicates a significant negative relationship between social support and psychological disorders including depression and stress (Alimoradi, Asadi, Asadbeigy, \&Asadniya, 2014; Bukhari \& Afzal, 2017).

\section{Conclusion}

As an exploratory study, findings are significant and useful in developing mental health support system and services to best help this group of students. Quality of school life for students with depressive condition were described 
through their experienced and perceived relationships with their support system especially their friends. Having friends in school are perceived by them as the most important influenced to experience quality school life. Moreover, the students expressed the significant contribution of accommodating and approachable student support services staff in school as well as the availability of different organizations that they participated and enjoyed with.

On the other hand, dysfunctional interpersonal interactions between identified influences are experienced by the students in this study. These major influences negatively hindered the students to experience quality of school life which focuses on their perceived relationships with their teachers and parents. Also, uncertainty of their career in the future is perceived by them as internal struggle in the present time. This is in contrast to the result of the study conducted by Javaal (2007) stating the contribution of the principal and the teachers as well as the parents. The devotion of the teachers and the caring interaction between teacher and student are perceived by them to be essential. Further the students express as important to get knowledge, as that is considered to give them the opportunity to improve their lives in the future.

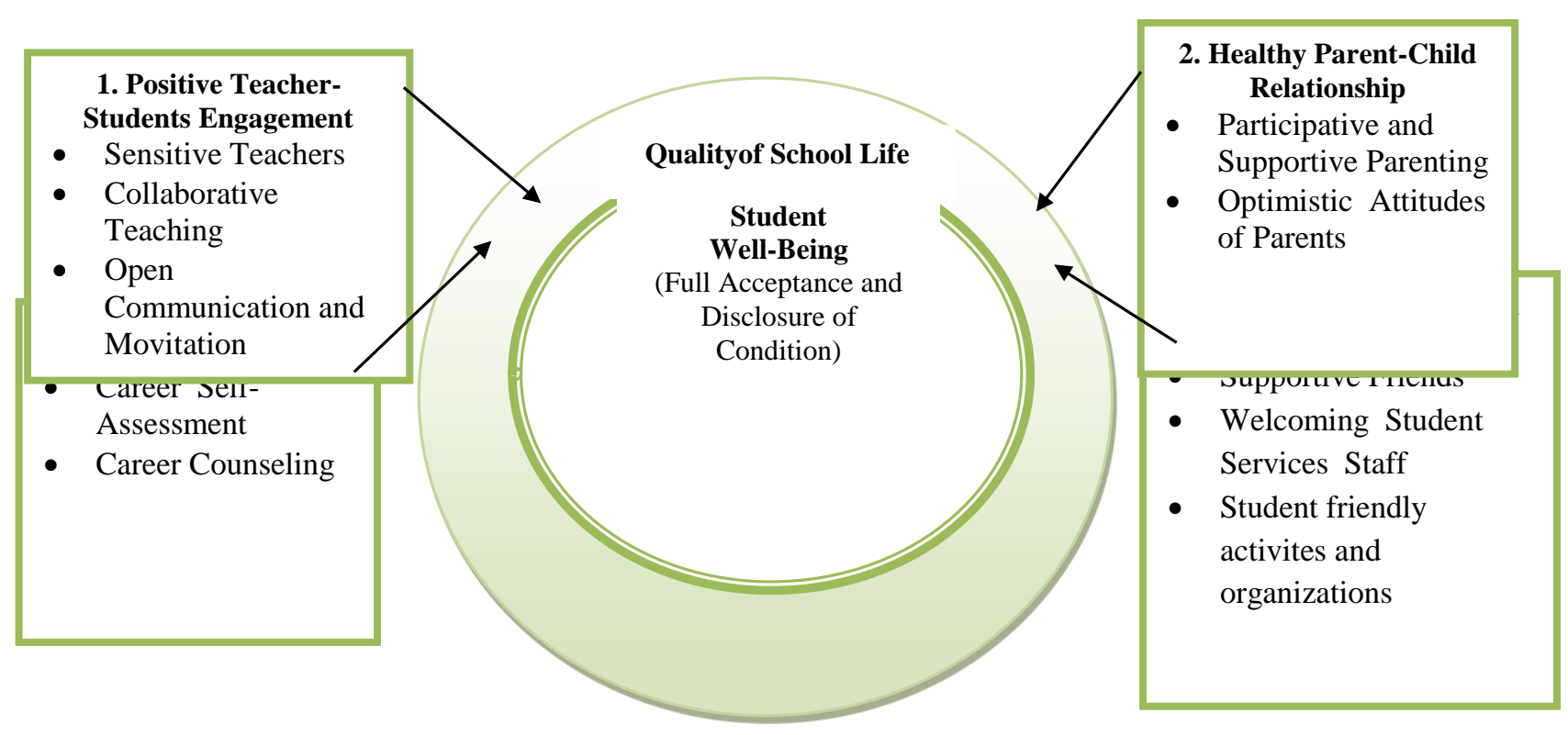

The diagram 1 generally shows the how students'interpretitively describe their experienced and perceived quality school life. These school influences were identified and perceived by them as their quality school life. These are positive teacher-students engagement, healthy parent-child relationships, clearcareer path and maintained or enhanced school support practices.

Moreover, the study concluded that students significantly aimed to have harmonious relationships with their teachers described as being sensitive to their needs, collaboratively and openly engaged them in class discussionsand understand and motivates them. Similar to the results of the study of Varga (2017), building and maintaining positive teacher-student relationships is essential for success in the classroom. These results suggest that classroom behavior can be improved through an enhancement in the relationships betweenteachers and students. Suggested interventions involved greeting studentsasthey entered the classroom and saying goodbye as they departed, which is something that 
everyteacher could include in his or her daily routine, and holding brief interpersonal conversationseach class period.

In line with healthy parent-child relationships, students value parent's involvement and participation with their school life fostering optimistic attitudes towards them. Takahiro Hasumi et.al (2012) investigated parental involvement and mental well being of Indian adolescents (13-14 yrs). The study revealed poor mental health was significantly associated with a decreased likelihood of parental involvement (low levels of depression, loneliness and anxiety). The study recommended health care professionals to encourage parents to be actively involved in adolescent's lives for development of psychological well being.

Futhermore, students' sigificantly seen the importance of clear career goals to their psychologcal well-being. This study is supported by Hull-Blanks et al. (2005), uncertainty about appropriate career path and lack of confidence in one's own ability to achieve career goals has been noted as negatively impacting college students' academic success and persistence. In order for college students to successfully choose an appropriate major, which they are often encouraged or even required to do during the first semester, they must have a clear idea of a career goal. This requires them to go through the career planning steps of self-assessment, exploration, and decision-making/action planning in a short period of time.

$$
\text { Lastly, maintained and }
$$
enhancedschoolsupportgroup practices were considered by the students as major influenced to their total well-being. Friends in school, student supports staffand student organizationsor activities should be continuously rendered and should be available for them to experience quality school life.

These influencesexpressed by them interplayed and interrelatedly plays an important part in their quality school life. In this study, Bronfenbrennerr's Ecological System Modelis found very usefulin understanding the interrelationshipof students to its identified school influences known as the individual microsystem in school. The microsystem is comprised by the most immediate and direct impact on the individual in the center. Referring to this study these include the relationship of students to their parents,teachers, staff and friends in school.Bronfenbrenner's work as cited by Taylor, R. D., \&Gebre, A. (2016)has provided a comprehensive conceptual rationale of how central social contexts in a child's life interact and influence key outcomes, including social and emotional adjustment and school performance and engagement.

\section{Recommendations}

In order to address the gap between students' perceived quality of school life with their identified school influences. A proposed mental health support system and services are hereby considered as part of the output of this research.The following mental health support system and services is identified:

\section{The Mental Health Support System and}

Services. The university under the Office of Counseling and Psychological Services should come up with responsive and dynamic services to contribute with students well-being. The multisectoral and multidisciplinary all systems approach are hereby categorized in to three (3) levels: University-Wide Support System Level, Group Support System Level and Individual Support System Level. 


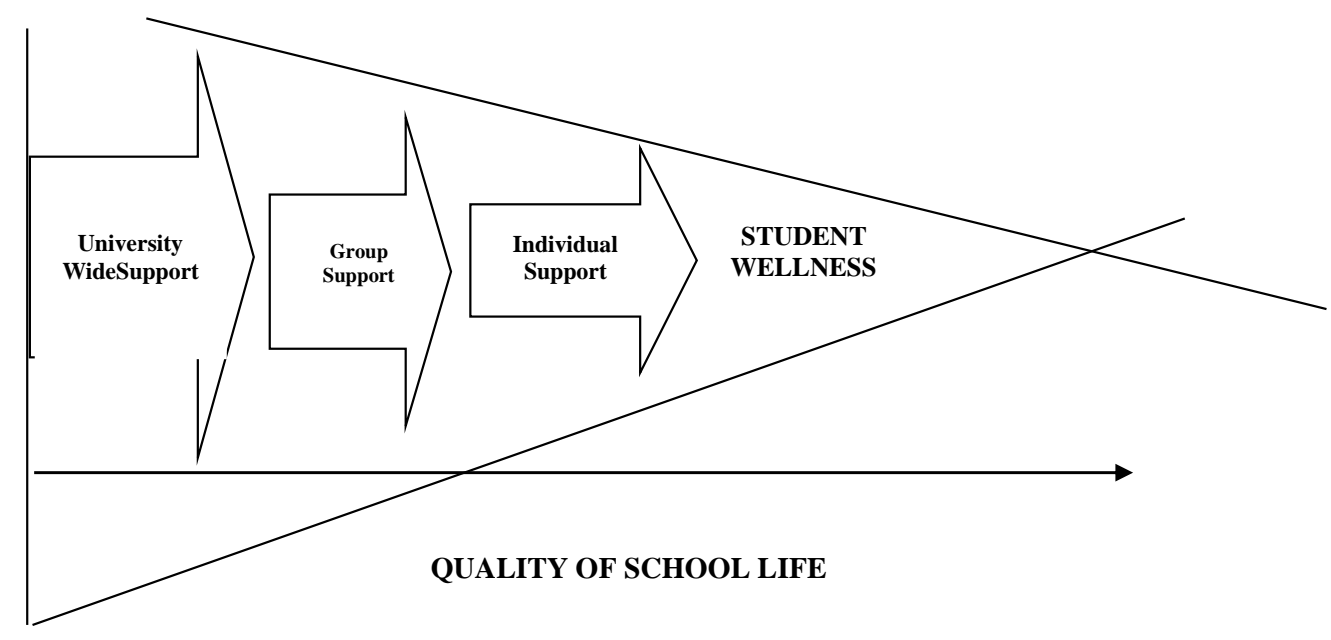

First, the University-Wide Support System Level, wherein the university is expected to design a concrete and responsive policies, guidelines and mechanism to integrate mental health services as part of the university priorities of giving quality service to all learners involving all members of the school community. Enhanced curriculum that integrates mental health domains and educational practices that prioritized learners' welfareand student support services that disseminates school-based awareness such as campaign and trainings for faculty. Also, "University Friendship Day" will be suggested as part of the activity to acknowledge the importance of friends to student's life especially in their psychological well-being.

More so, teachers both regular and parttime must assess their student' profile. Recognizing individual differences should be considered especially having students with psycho-social disability. Furthermore, proactive teacher-student engagement should be encouraged and initiatively part of the learning process in order to promote positive interactions. Sensitivity and mental health awareness seminar should be part of the teacher's training especially on intensive identification and early detection of learner's profile, interactive classroom engagement strategies and proactive used of referral mechanism. Teachers should be educated with the signs and symptoms of depression. . Classroom orientation conducted every beginning of the semester should not limited only on house rules, academic requirements, grading system and topics to be discussed but a profiling strategy of getting to know the students' personal, social and psychological information.

Group Support System Level, the second prevention and intervention support system level focused on the significant contribution of the support group such as friends, teachers and parents as well as organizations that advocates mental health. Having friends in school as the major influence in students' wellbeing will be heightened by giving importance on the benefits of act of friendliness. Peer counseling group, teacher group advising and parent-counseling group are among of the considered activities that suggests to facilitate group process and structured learning activities for students.Parents-school collaboration such as regular coordination and monitoring of students with depression should be given emphasis.

\section{Lastly, Individual Support System}

Level, in this level, one on one responsive intervention program should be given such as regular monitoring and coordination with students through individual counseling and follow-ups. The role of the guidance and counseling office in the dissemination of mental health services through closed coordination with the school 
administrators, class adviser, subject-teachers and student body on the importance of guidance services such as individual counseling, follow-up, consultation and case conference are hereby considered.Counseling should be extended to parents if possible to allow parents understand their important role in the psychological wellbeing of their children. More so, career counseling should be given to those confused and undecided incoming students on their career interest.

\section{Conflict of Interest}

We certify that there is no conflict of interest with any financial, personal, or other relationships with other people or organization related to the material discussed in the manuscript.

\section{Acknowledgements}

The authors would like thank the Polytechnic University of the PhilippinesResearch Management Office for their enthusiastic encouragement to the faculty members to continuously hone the latter research skills, to PUP Quezon City Administration in allowing and providing support to the researchers from the start and up to the time this research study was completed, to their Guidance and Counselling Office in the provision of pertinent data from the participants meticulously following the ethical procedure in making such kind of research.

\section{References}

[1] Alimoradi, M., Asadi, H., Asadbeigy, H., \&Asadniya, R. (2014).published in Social Science and Medicine, UCLA sociology professor S. Michael Gaddis examined data from the Healthy Minds Study,

[2] Alsubaie M.M. et. Al. (2018). The role of sources of social support on depression and quality of life for university students. International Journal of Adolescence and Youth. Oct 2018, Volume 24, 2019 - Issue 4.
[3] American Psychiatric Association. (1994). Diagnostic and Statistical Manual of Mental Disorders (4th ed.). Washington, DC: Authors

[4] Babbie, E. and Mouton, J. (2010) The Practice of Social Research. 10th Edition, Republic of South Africa, Oxford University Press Southern Africa, Cape Town.

[5] Braun, V., \& Clark, V. (2006). Using thematic analysis in psychology. Qualitative Research in Psychology, 3, 77-101.

[6] Bukhari1, S. R,Afzal, F. (2017). Perceived Social Support predicts Psychological Problems among University Students. The International Journal of Indian Psychology. ISSN 2348-5396 (e) | ISSN: 2349-3429 (p)

[7] Cresswell JW, Plano Clark VL. Designing and conducting mixed method research. 2nd Sage; Thousand Oaks, CA: 2011. [Google Scholar]

[8] Crundwell, R. Marc and Killu, Kim (2010). Responding to a Student's Depression. Retrieved from: http://www.ascd.org/publications/educationa 1-

leadership/oct10/vol68/num02/abstract.aspx \#Responding_to_a_Student's_Depression

[9] Dauliwal (2019). Patterns of Relationships Between Teacher Engagement and Student Engagement. Education Doctoral Ralph C. Wilson, Jr. School of Education 8-2011. Fisher Digital Publications

[10] Evans, D. L., \& Andrews, L. W. (2005). If your adolescenthas depression or bipolar disorder. New York: OxfordUniversity Press.

[11] Eyre W., Thomas House, Edward M. Hill and Frances E. Griffiths (2017). Spreading of components of mood in adolescent social networks Robert Published: https://doi.org/10.1098/rsos.170336

[12] Gay, Geneva (2001). Culturally ResponsiveTeaching: Theory, Research, and Practice, American Association of Colleges 
for Teacher Education. University of Washington, Seattle

[13] Goodman SH, Gotlib IH. Risk for psychopathology in the children of depressed mothers: A Developmental model for understanding mechanisms of transmission. Psychological Review. 1999;106:458-490. [PubMed] [Google Scholar]

[14] Hasumi, T., Ahsan, F., Couper, C. M., Aguayo, J. L., \& Jacobsen, K. H. (2012). Parental involvement and mental well-being of Indian adolescents. Indian pediatrics, 49(11), 915-918.

[15] Huberty, T. J. (2008). Best practices in school-basedinterventions for anxiety and depression. Available: http://www.nasponline.org/publications/cq/c q353depression.Aspx

[16] Huberty, T. J. (2006). Depression: Helping students in theclassroom. Communique', 35(3).

Available:

http://www.nasponline.org/publications/cq/c q353depression.Aspx

[17] Hull-Blanks, E., Kurpius, S. E., Befort, C., Sollenberger, S., Nicpon, M., \&Huser, L. (2005). Career goals and retention-related factors among college freshmen. Journal of Career Development, 32, 16-30.

[18] Kane P, Garber J. (2004). The relations among depression in fathers, children's psychopathology, and father-child conflict: A meta-analysis. Clinical Psychology Review. 2004;24:339-360. [PubMed] [Google Scholar]

[19] Keith, Tiana (2016). Depression and its Negative Effects on College Students. East Carolina University.

[20] Law et. At. (2015). Helping highly anxious clients embrace chaos and career uncertainty using cognitive behaviouraltechniques.Australian Journal of Career Development (Sage Publications Ltd.). Apr2014, Vol. 23 Issue 1, p29-36.
8p.Published online 2014 Aug 21. doi: 10.1007/s40596-014-0205-9

[21] Marmorstein NR, Iacono WG (2004). Major depression and conduct disorder in youth: Associations with parental psychopathology and parent-child conflict. Journal of Child Psychology and Psychiatry. 2004;45:377386. [PubMed] [Google Scholar]

[22] Merrell, K. (2004).Helping students overcome depression and anxiety: National Association of School Psychologists.

[23] Parehk, Ranna2017. American Psychiatric Association. Diagnostic and Statistical Manual of Mental Disorders (DSM-5), Fifth edition

[24] R. Marc A. Crundwell and Kim Killu (2010). Responding to a Student's Depression. Interventions That Work Pages 46-51, Volume 68, Number

[25] Robotham, D. (2008). Stress among higher education students: Towards a research agenda. Higher Education, 57(1), 735746.[Crossref] , [Google Scholar]

[26] Ryan G. \& Bernard H. (2003). Techniques to Identify Themes. Research Article. https://doi.org/10.1177/1525822X02239569

[27] World Health Organization (2007). Research capacity for mental health in low- and middle income countries. Global Forum for Health Research and World Health Organization 2007. ISBN 2-940286-54-X

[28] Safree,M.A., Yasin,M, Dzulkifli,M.A.(2009). Differences in psychological problems between low and high achieving students. The journal of Behavioral Science. 4(1) 49-58.

[29] Sarokhani, D. et. al. (2013). Prevalence of Depression among University Students: A Systematic Review and Meta-Analysis Study. Depression research and treatment.

[30] Schneider J., 2017. What Makes A Great School. Harvard Graduate School of Education. 
[31] Sharon Feiman-Nemser(2008).Teacher Presentation: Structural and Conceptual Alternatives Conceptual Orientations in Teacher Education. Handbook of Research on Teacher Education. New York. https://www.education.msu.edu/NCRTL/PD Fs/NCRTL/IssuePapers/ip902.pdf

[32] Sheeber L, Sorenson E. Family relationships of depressed adolescents: A multimethod assessment. Journal of Clinical Child Psychology. 1998;27:268-277. [PubMed] [Google Scholar]

[33] Sreeramareddy CT1, Shankar PR, Binu VS, Mukhopadhyay C, Ray B, Menezes RG (2007). Psychological morbidity, sources of stress and coping strategies among undergraduate medical students of Nepal.Department of Community Medicine, Manipal College of Medical Sciences, Pokhara, Nepal.

[34] Stice E, Ragan J, Randall P. Prospective relations between social support and depression: Differential direction of effects for parent and peer support. Journal of
Abnormal Psychology. 2004;113:155-159. [PubMed] [Google Scholar]

[35] Tangen, R. (2009). Conceptualising quality of school life from pupils' perspectives: a four-dimensional model. International Journal of Inclusive Education. 13:8, 829844, DOI: 10.1080/13603110802155649.

[36] Taylor, R. D., \&Gebre, A. (2016). Teacherstudent relationships and personalized learning: Implications of person and contextual variables. In M. Murphy, S. Redding, \& J. Twyman (Eds.), Handbook on personalized learning for states, districts, and schools (pp. 205-220). Philadelphia, PA: Temple University, Center on Innovations in Learning. Retrieved from www.centeril.org

[37] Thomas \& J. Grimes (Eds.), Best practices in schoolpsychology V (pp. 14731486).Bethesda, MD:

[38] Varga, Meagan (2017).The Effect of Teacher-Student Relationships on the Academic Engagement of Students. Graduate Programs in Education. Goucher College 
APPENDICES

\section{APPENDIX 1- Guide Questions}

1. How do you describe your school life?

2. How do you perceived your school life?

3. What do you likes or dislikes in school?

4. What influences your school life?

APPENDIX 2- The schematic summary of the identified major themes and subthemes.

\begin{tabular}{|c|c|c|}
\hline DESCRIPTION & CODING & THEMES \\
\hline $\begin{array}{l}\text { antipathy } \\
\text { tackles } \\
\text { careless jokes on insanity } \\
\text { personal attack }\end{array}$ & Insensitive Teachers & \multirow{4}{*}{$\begin{array}{l}\text { Poor Teacher -Student } \\
\text { Classroom Engagement }\end{array}$} \\
\hline $\begin{array}{l}\text { too focused on lesson } \\
\text { too serious on the topic }\end{array}$ & Lesson-Focused Discussion & \\
\hline $\begin{array}{l}\text { done with Senior High } \\
\text { know everything } \\
\text { expecting everyone to know the } \\
\text { topic discussed }\end{array}$ & High Expectations for Students & \\
\hline $\begin{array}{l}\text { cannot understand the condition } \\
\text { no plan of telling the case to } \\
\text { subject teachers }\end{array}$ & $\begin{array}{l}\text { Non- Disclosure of Condition to } \\
\text { Subject Teachers }\end{array}$ & \\
\hline $\begin{array}{l}\text { not concerns since grade school } \\
\text { not supportive for check up }\end{array}$ & Uninvolved-Unsupported Parents & \multirow[b]{2}{*}{$\begin{array}{c}\text { Dysfunctional } \\
\text { Parent-Child Relationships }\end{array}$} \\
\hline $\begin{array}{l}\text { "stigma at home" } \\
\text { making "dramas" } \\
\text { labelled as "insane" }\end{array}$ & Stigmatizing Attitudes of Parents & \\
\hline
\end{tabular}




\begin{tabular}{|c|c|c|}
\hline $\begin{array}{l}\text { many math subjects } \\
\text { math as weak spot } \\
\text { difficult major subjects } \\
\text { "heavy days" due to subjects and } \\
\text { prof }\end{array}$ & $\begin{array}{l}\text { Struggle on Major and Math } \\
\text { Related Subjects }\end{array}$ & \\
\hline $\begin{array}{l}\text { not connected to interest } \\
\text { fond of handicrafts and events } \\
\text { ICT is father's suggestion } \\
\text { plan of shifting }\end{array}$ & $\begin{array}{l}\text { Perceived Unrelatedness of } \\
\text { Enrolled Program to Career } \\
\text { Interest }\end{array}$ & $\begin{array}{c}\text { Personal Uncertainty for } \\
\text { Future Career }\end{array}$ \\
\hline $\begin{array}{l}\text { very supportive friends } \\
\text { build strength } \\
\text { helping in academic requirement } \\
\text { support group } \\
\text { many friends in other courses } \\
\text { value them over family }\end{array}$ & 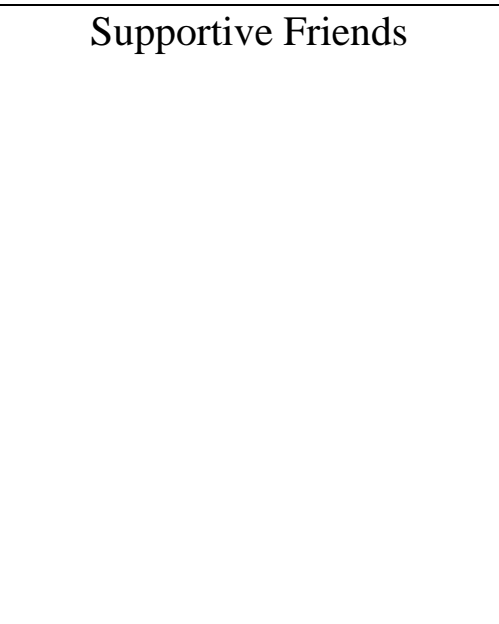 & $\begin{array}{c}\text { Welcoming School Support } \\
\text { System }\end{array}$ \\
\hline $\begin{array}{l}\text { kind and accommodating staff } \\
\text { security officer is kind } \\
\text { registrar and admission are } \\
\text { accommodating }\end{array}$ & $\begin{array}{c}\text { Approachable and } \\
\text { Accommodating Staff }\end{array}$ & \\
\hline $\begin{array}{l}\text { kind officers } \\
\text { friendly organizations } \\
\text { activities are enjoyable }\end{array}$ & $\begin{array}{c}\text { Participation in Students } \\
\text { Organizations and School } \\
\text { Activities }\end{array}$ & \\
\hline
\end{tabular}

